\title{
Socio-Ecological Practice Research (SEPR): What does the journal have to offer?
}

\author{
Wei-Ning Xiang ${ }^{1}$
}

Published online: 12 October 2018

(c) Springer Nature Singapore Pte Ltd. 2018

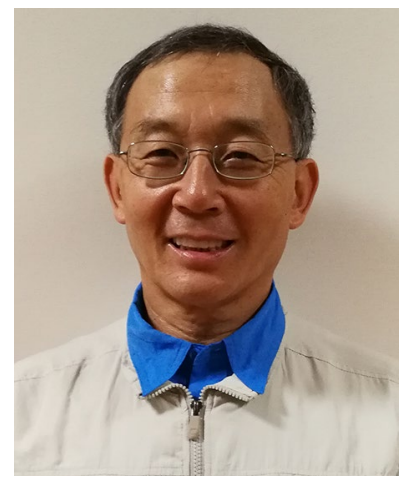

The founding editor-in-chief

\section{A mission}

The journal Socio-Ecological Practice Research (SEPR) publishes scholarly articles on socio-ecological practice research, a transdisciplinary inquiry that strives to achieve the dual ambition of producing new knowledge and improving socio-ecological practice. It provides this service to the international communities of scholars and practitioners who work on or are interested in issues pertaining to the socio-ecological practices of planning, design, construction, restoration, and management. By doing so, SEPR aims to cultivate and celebrate topnotch scholarship in Ecopracticology, the study of socio-ecological practice (Xiang 2019, this issue), across all four intertwining streams of scholarly inquiry-knowledge (co)production, transfer, implementation, and impact - with a focus on knowledge implementation and impact research (knowledge I\&I research).

Wei-Ning Xiang

wxiang@uncc.edu

1 Department of Geography and Earth Sciences, University of North Carolina at Charlotte, Charlotte, NC 28223, USA

\section{A fleet of scholarly articles}

The eleven types of SEPR articles contribute to this enterprise from a suite of distinct yet complementary angles and thus fall into five clusters of Research, Retrospect, Opinion, Showcase, and Special Issues (Table 1).

\subsection{SEPR Research Articles}

Each of the four types of SEPR Research Articles reports a class of socio-ecological practice research conducted from a specific angle and within a particular quadrant in the Schön-Stokes model of research in socio-ecological systems (Fig. 1).

\subsubsection{Practice research on knowledge coproduction}

An SEPR article of practice research on knowledge coproduction presents an original research conducted in Pasteur's quadrant (Fig. 1; for discussions on research in Pasteur's quadrant, see Xiang 2017, pp. 2244-2246). It describes how scholarly rigorous knowledge was generated that was useful-directly relevant, immediately actionable, and foreseeably efficacious - to the real-world practitioners who were in specific knowledge needs under particular circumstances of socio-ecological practice; it further demonstrates how the high caliber scholarship built through the research can be inspirational to scholars and practitioners from around the world who have comparable interests in socio-ecological practice research.

\subsubsection{Applied basic research on knowledge transfer}

An SEPR article of applied basic research on knowledge transfer presents an empirical research done in Bohr's quadrant (Fig. 1; for discussions on applied basic research and pure basic research in Bohr's quadrant, see Xiang 2017, pp. 2242-2243). It demonstrates, through experiment or case 
Table 1 SEPR article types by clusters

\begin{tabular}{|c|c|c|c|c|c|}
\hline & \multicolumn{5}{|l|}{ Cluster } \\
\hline & Research & Retrospect & Opinion & Showcase & Special Issues \\
\hline \multirow[t]{4}{*}{ Article type } & Practice research & Review & Perspective essays & \multirow[t]{4}{*}{ Showcase } & \multirow{4}{*}{$\begin{array}{l}\text { Any combination of the } \\
\text { preceding article types }\end{array}$} \\
\hline & Applied basic research & $\begin{array}{l}\text { Reflective essays and intellectual } \\
\text { (auto)biographies }\end{array}$ & Communications & & \\
\hline & Action research & & Comments and rejoinders & & \\
\hline & Follow-up research & & Editorials & & \\
\hline
\end{tabular}

\begin{tabular}{l|l|l|}
$\begin{array}{ll}\text { Quest for } \\
\text { fundamental } \\
\text { understanding }\end{array}$ & $\infty \begin{array}{l}\text { Bohr's quadrant } \\
\text { of pure basic } \\
\text { research } \\
\text { or applied basic } \\
\text { Interest in } \\
\text { theoretical } \\
\text { problems }\end{array}$ & $\begin{array}{l}\text { Pasteur's quadrant } \\
\text { of use-inspired } \\
\text { basic research for } \\
\text { practice /practice } \\
\text { research }\end{array}$ \\
\cline { 2 - 3 } & $\begin{array}{l}\text { Johnson's } \\
\text { quadrant of free } \\
\text { roaming, a } \\
\text { precursor of } \\
\text { research in other } \\
\text { quadrants }\end{array}$ & $\begin{array}{l}\text { Edison's quadrant } \\
\text { of pure applied } \\
\text { research /action } \\
\text { research }\end{array}$ \\
\cline { 2 - 2 } & 0 &
\end{tabular}

Consideration of use \&

Interest in practical problems

Fig. 1 The Schön-Stokes model of research in socio-ecological systems (After Xiang 2017, p. 2243) [Xiang (2017) retrofitted Stokes's (1997) model with Schön's ideas (2001) for its use in a broader context of socio-ecological systems, and named the retrofit the SchönStokes model of research in socio-ecological systems. For the seminal articulation of the original model, see Stokes (1997, pp. 70-75).]

study, how the scholarly theories, scientific methods, and techniques developed by scholars of pure basic research in the same quadrant (Ibid.) can be made relevant to and actionable for the solution of problems real-world practitioners care about; recognizing the challenges this knowledge transfer process faces, it offers caveats as well as recommendations to practitioners pertaining to necessary measures of adaptation in actual use.

\subsubsection{Action research on knowledge implementation}

An SEPR article of action research on knowledge implementation presents a professional project completed in Edison's quadrant (Fig. 1; for discussions on research in Edison's quadrant, see Xiang 2017, pp. 2242-2244). It showcases how the existent scholarly theories, scientific methods, and techniques were actually employed in socio-ecological practice to achieve the applied goal(s) of problem-solving; without seeking a thorough investigation of the scientific principles underlying the suggested solution(s), it shares the experience, lessons, caveats, and reflections of the participating scholars and practitioners.

\subsubsection{Follow-up research on knowledge I\&I}

All the three types of Research Articles above-mentioned are accompanied by a sequel type of follow-up research. An SEPR article of follow-up research on knowledge I\&I features an assessment that is performed in Johnson's quadrant and can serve as a precursor of research in other three quadrants [Fig. 1; for discussions on research in Johnson's quadrant, see Xiang (2017, p. 2243), and Xiang (2018)]. It tracks and evaluates the state of the practice-the practical implementation and ensuing impacts-of the new knowledge generated in a previous study and reported in credible publications. Pertinent research questions include, but are not limited to, the following [adapted from Xiang (2017, p. 2241)]:

Was the new knowledge ever delivered to and accepted by the designated practical beneficiaries-planners, designers, engineers, managers, or decision-makers? Was it actually used in their practice? Was it effective in helping produce desirable or expected results they care about? What kind of and how much difference in their practice did the implementation of the knowledge make, if at all? Why or why not? What could have been done differently for the better?

Typically, 2 or 3 years after their research articles have been published in SEPR, authors are invited to write knowledge $I \& I$ research articles and submit for publication considerations. Unsolicited proposals for knowledge I\&I research articles by researchers who are not authors of SEPR-published articles will be equally welcomed. Furthermore, knowledge $I \& I$ research articles are forever solicited that assess the state of the practice of SEPR pertinent works reported in other journals. 


\subsection{SEPR Retrospect Articles}

The two types of SEPR Retrospect Articles, respectively, present socio-ecological practice research reviews, and feature intellectual reflections on scholarly or professional experience.

\subsubsection{Review articles}

An SEPR review article systematically assesses the state of the practice of policy instruments, industrial standards, or professional guidelines in socio-ecological practice [e.g., European Landscape Convention, the Active Beautiful Clean (ABC) Waters Program in Singapore, the Sustainable SITES Initiative]; it may also critically examine the state of the art of theories, methods, or techniques in a pertinent knowledge domain (e.g., ecosystem services valuation in ecological planning, landscape performance assessment, urban growth modeling, soil sequestration, urban renewal, collaborative rationality, land ethic, and ecological wisdom). In both cases, it scrutinizes through either a panoramic lens of knowledge (co)production-transfer-implementation-impact or a more-focused lens of knowledge I\&I. In addition, an SEPR review article may seek insights from philosophical lenses of ontology, epistemology and methodology, and share with the journal community of often less philosophical readers.

Compared with the follow-up research articles on knowledge I\&I, SEPR review articles cover a broader range of topical areas and a greater time span (e.g., a review on the socio-ecological impacts of $A$ Sand County Almanac, a 1949 book by Aldo Leopold).

\subsubsection{Reflective essays and intellectual (auto)biographies ${ }^{1}$}

An SEPR reflective essay presents personal convictions or reflections of scholars and practitioners on issues pertaining to knowledge (co)production, transfer, implementation, and impact in socio-ecological practice. It may take the form of an intellectual autobiography in which the author describes the emergence and evolution of scholarly ideas as an integrated part of the unfolding and procession of her/his scholarly career. It may also take the form of an intellectual biography of a respected scholar or practitioner of international influence. In both cases, an intellectual biography or autobiography serves as an instrument of socio-ecological practice research to celebrate and cultivate what C. Wright

\footnotetext{
1 The idea for this article type is inspired by Haselsberger (2017). The 16 essays of intellectual autobiography the volume features are examples prospective SEPR authors can emulate in their autobiographical essay writing.
}

Mills calls a quality of mind that fuses rigorous research and personal experience (Mills 1959, pp. 5-6) for a well-lived, fully realized, and meaningful life (Xiang 2016, p. 54).

\subsection{SEPR Opinion Articles}

The four types of SEPR Opinion Articles provide forums for expression of ideas and open discussions.

\subsubsection{Perspective essays}

An SEPR perspective essay presents scholarly or professional opinions on issues pertaining to knowledge (co) production, transfer, implementation, and impact in socioecological practice. It may also present new ideas on emerging or enduring topics in socio-ecological practice research.

\subsubsection{Communications}

An SEPR communication succinctly presents and analyzes an issue, a "hot" topic, an intriguing idea, or a controversy that, either immerging or enduring, falls within the SEPR scope and is of interest to the journal community.

\subsubsection{Comments and rejoinders}

An SEPR comment is a note on an article published in SEPR through which non-author scholars and practitioners make critical or complimentary comments, or call for further investigations. Authors of the previously published article which the comment is made upon are offered the opportunity to respond with a rejoinder which may be published together with the comment.

\subsubsection{Editorials}

An SEPR editorial is a forum for the editor-in-chief or invited guests to share perspectives on pertinent issues, introduce special issue essays, and communicate matters relevant to the journal community.

\subsection{SEPR Showcase Articles}

An SEPR showcase presents exemplars of successful socioecological practice from around the world and throughout human history. For each instance featured, it offers insights into the key reasons for success through the knowledge $I \& I$ lens and highlights the roles scholars and practitioners played in the process. 


\subsection{SEPR Special Issues}

An SEPR Special Issue (SI) is a coherent collection of 10-15 articles on an important emerging or enduring theme in socio-ecological practice research that has a broad international appeal. Each SI entry is an SEPR article from one of the above-mentioned four clusters and contributes to the collective caliber of the special issue.

\section{A set of important commonalities}

All five clusters of SEPR articles share a set of commonalities that enhances the effectiveness of their scholarly presentations of socio-ecological practice research.

\subsection{Attentiveness to the dual ambition}

All SEPR articles are equally attentive to the dual ambition of producing new knowledge and improving socio-ecological practice; they are reflective of SEPR's overarching motto "From practice, for practice, beyond practice" in distinct yet equally meaningful ways.

\subsection{Interest in the usefulness of knowledge}

All SEPR articles take a genuine interest in the usefulness of knowledge to both scholars and practitioners; they regard as a benchmark for exemplary socio-ecological practice research the tripartite requirement for knowledge usefulness-direct relevance, immediate actionability, and foreseeable efficacy.

\subsection{Commitment to scholarly rigor}

All SEPR articles are committed to scholarly rigor; they demonstrate and celebrate the effectiveness of a broad array of approaches from sciences and humanities in rigorous socio-ecological practice research.

\subsection{Writing with style, accuracy, brevity, and clarity}

All SEPR articles engage and inform readers in a straightforward yet elegant manner through stylish writing; they are effective academic prose of accuracy, brevity, and clarity that speaks eloquently to both academic and professional audiences. $^{2}$

\footnotetext{
$\overline{2}$ Two useful reference books on stylish academic writing are Clear and simple as the truth: writing classic prose (second edition) by Thomas and Turner (2011) and Stylish academic writing by Hellen Sword (2012).
}

\subsection{The quality of international appeal}

All SEPR articles are crafted appealing to the international communities of scholars and practitioners; they present research of local, regional, or national importance within an international context and elaborate in ways understandable and intriguing to the international audience.

\section{The prospects}

In summary, with a fleet of scholarly articles that provides quality services to the international communities of scholars and practitioners, the journal Socio-Ecological Practice Research (SEPR) is well positioned to pursue the mission of cultivating and celebrating topnotch scholarship in Ecopracticology and contributes, through this endeavor, to the communities' collective quest for the greater good (Anonymous 2013).

Acknowledgements I wish to thank the following individuals whose work and ideas inspired and helped the development of this editorial (in alphabetic order): Varenyam Achal (Guangdong TechnionIsrael Institute of Technology, China), Christian Albert (University of Hannover, Germany), Ian Bishop (The University of Melbourne, Australia), Steven Cooke (Carleton University, Canada), Christopher Cvitanovic (CSIRO Oceans \& Atmosphere, Australia), Christine Fürst (Martin Luther University of Halle-Wittenberg, Germany), Shu-Li Huang (National Taipei University, Taipei, Taiwan), Klaus Hubacek (University of Maryland, USA), Judy Innes (University of California at Berkeley, USA), C.Y. Jim (Education University of Hong Kong, China), Buyana Kareem (Makerere University, Uganda), Daniele La Rosa (University of Catania, Italy), Steffen Lehmann (University of Portsmouth, UK), Kuei-Hsien Liao (National Taipei University, Taiwan), Paul Opdam (Wageningen University Research Center, The Netherlands), Duncan Patten (Arizona State University, USA), Stephan Pauleit (Technical University of Munich, Germany), Steven Pinker (Harvard University, USA), Qing Shen (University of Washington, USA); Fritz Steiner (University of Pennsylvania, USA), Hui Wang (Nanjing University of Forestry, China), Xinhao Wang (University of Cincinnati, USA), Yuncai Wang (Tongji University, China), Jianguo Wu (Arizona State University, USA), Wentao Yan (Tongji University, China), Bo Yang (University of Arizona, USA), Xingzhong Yuan (Chongqing University, China).

\section{References}

Anonymous (2013) The greater good. Nature 505(7481):5

Haselsberger H (2017) Encounters in planning thought: 16 autobiographical essays from key thinkers in spatial planning. Routledge, New York and London

Mills CW (1959) Sociological imagination. Oxford University Press, Oxford

Schön D (2001) The crisis of professional knowledge and the pursuit of an epistemology of practice. Chapter 13, In: Raven J, Stephenson J (eds) Competence in the learning society. pp 185-207. Reproduced on the HE Academy website by kind permission of Peter Lang Publishing, Inc. Retrieved online from http://wwwnew1.heaca demy.ac.uk/assets/documents/resources/heca/heca_cl13.pdf 
Stokes DE (1997) Pasteur's quadrant: basic science and technological innovation. Brookings Institution Press, Washington, DC

Sword H (2012) Stylish academic writing. Harvard University Press, Cambridge

Thomas F-N, Turner M (2011) Clear and simple as the truth: writing classic prose, 2nd edn. Princeton University Press, Princeton

Xiang W-N (2016) Ecophronesis: the ecological practical wisdom for and from ecological practice. Landscape Urban Plann 155:53-60

Xiang W-N (2017) Pasteur's quadrant: an appealing ecophronetic alternative to the prevalent Bohr's quadrant in ecosystem services research. Landsc Ecol 32(12):2241-2247. https://doi.org/10.1007/ s10980-017-0583-y

Xiang W-N (2018) Correction to: Pasteur's quadrant: an appealing ecophronetic alternative to the prevalent Bohr's quadrant in ecosystem services research. Landsc Ecol 33(1):171. https://doi. org/10.1007/s10980-017-0596-6

Xiang W-N (2019) Ecopracticology: the study of socio-ecological practice. Socio-Ecol Pract Res 1(1) 